\title{
GERMINAÇÃO E VIGOR DE SEMENTES DE MUTAMBA (Guazuma ulmifolia Lam.) EM DIFERENTES TEMPERATURAS E SUBSTRATOS
}

Brenna Rafaella Verissimo dos Santos ${ }^{1}$, Kleane Targino Oliveira Pereira ${ }^{1}$, Erivanessa Costa Sousa ${ }^{1}$, Tatianne Raianne Costa Alves ${ }^{2}$ Clarisse Pereira Benedito ${ }^{3}$

1. Mestrandas do Programa de Pós-graduação em Fitotecnia, Universidade Federal Rural do Semi-Árido/ Mossoró - RN (bre.rafa@hotmail.com).

2. Estudante de graduação em Agronomia, Universidade Federal Rural do Semi-Árido/ Campus de Mossoró - RN

3. Professora do Centro de Ciências Agrárias da Universidade Federal Rural do Semi-Árido (UFERSA), Mossoró - RN

Recebido em: 08/04/2017 - Aprovado em: 10/06/2017 - Publicado em: 20/06/2017 DOI: 10.18677/EnciBio_2017A59

\section{RESUMO}

Guazuma ulmifolia Lam. também conhecida como mutamba é uma espécie nativa da América do Sul, utilizada principalmente como madeireira e para programas de reflorestamento, sendo multiplicada por sementes. A análise de sementes desta espécie é dificultada, pois não há padronização nas Regras para Análise de Sementes com relação a temperatura e substrato para condução do teste de germinação. Sendo assim, objetivou-se avaliar a germinação e o vigor de sementes de G. ulmifolia em diferentes temperaturas e substratos. $O$ delineamento experimental foi o inteiramente casualizado (DIC), em um esquema fatorial $3 \times 4$ (temperaturas $x$ substratos), totalizando 12 tratamentos com quatro repetições de 25 sementes. Os substratos foram: sobre papel (SP), entre papel (EP), entre areia (EA) e rolo de papel (RP), sob as temperaturas de $25^{\circ}$ e $30^{\circ} \mathrm{C} 20-30^{\circ} \mathrm{C}$, com fotoperíodo de 8 horas. As variáveis analisadas foram: germinação, tempo médio de germinação, índice de velocidade de germinação, comprimento da parte aérea e da raiz e massa seca total de plântulas. A germinação e o vigor de sementes de $G$. ulmifolia podem ser avaliados na temperatura de $25^{\circ} \mathrm{C}$ nos substratos entre papel ou sobre papel.

PALAVRAS-CHAVE: análise de sementes, malvaceae, qualidade fisiológica.

\section{GERMINATION AND VIGOR OF SEEDS MUTAMBA (Guazuma ulmifolia LAM.)}

\begin{abstract}
Guazuma ulmifolia Lam. also known as mutamba is a specie native to South America, is an arboreal species with large potential socioeconomic and ecological. Thus, this work was developed with the objective of evaluating temperatures and substrates for mutamba germination due to lack of information on this species. In addition, the germination is influenced by environmental factors, when properly manipulated; optimize the results give vigorous seedling. The experiment was conducted at the Seed Analysis Laboratory of the Federal Rural University of the Semi-Arid (UFERSA). The experimental design was completely randomized (DIC), in a factorial $3 \times 4$ (temperature $\times$ substrate), totaling 12 treatments with four
\end{abstract}


replications of 25 seeds. The substrates were on blotting paper, between blotting paper, between sand and paper roll at constant temperatures of $25^{\circ} \mathrm{C}, 30{ }^{\circ} \mathrm{C}$ and alternating $20-30{ }^{\circ} \mathrm{C}$, where the following variables were analyzed: germination (\%), mean germination time (AGT), speed index germination (IVG) and seedling dry matter (MSP). The temperature of $25^{\circ} \mathrm{C}$ between the substrate paper and on paper mutamba are suitable for seed germination.

KEYWORDS: Malvaceae, seed analyses, physiological quality.

\section{INTRODUÇÃO}

Guazuma ulmifolia Lam. é uma espécie pertencente a família Malvaceae, conhecida popularmente como mutamba, mutambo, fruta-de-macaco, mutambaverdadeira, ocorre em toda América tropical, no Brasil desde a Amazônia até o Paraná (LORENZI, 2002). Além disso, é uma espécie que tem grande potencial como madeireira,utilizada na confecção de tonéis, carvão e fabricação de pólvora (BEWLEY \& BLACK,1994).

O processo de germinação das sementes pode ser influenciado por diversos fatores ambientais, como substrato e temperatura os quais podem ser manejados a fim de otimizar a percentagem, velocidade e uniformidade de germinação, tendo como resultado a obtenção de plântulas mais vigorosas e na redução de gastos de produção (NASSIF et al., 2004). Isto acontece por influenciar diretamente na absorção de água pela semente e nas reações bioquímicas que regulam todo 0 processo metabólico (BEWLEY \& BLACK, 1994). Dessa forma, é importante conhecer as condições apropriadas para que este processo de germinação aconteça normalmente, especialmente porque as espécies apresentam respostas diferentes em função de alguns fatores internos como dormência, viabilidade ou condições ambientais, como: água, temperatura, oxigênio, luz e ausência de patógenos (CARVALHO \& NAKAGAWA, 2012).

A temperatura influencia diretamente sobre a velocidade e na porcentagem final de germinação (CARVALHO \& NAKAGAWA, 2012). As sementes possuem um comportamento variável e não há uma temperatura ótima e uniforme para a germinação de todas as espécies. Por isso, recomenda-se uma faixa de 20 a $30{ }^{\circ} \mathrm{C}$ como temperaturas propícias para germinação de muitas espécies tropicais e subtropicais (GUEDES et al., 2011).

O substrato é outro fator importante a ser considerado, pois atua como base onde as sementes são postas para germinar, obtendo condições apropriadas para o desenvolvimento do processo, assim como para o crescimento e desenvolvimento posterior das plântulas (FERREIRA et al., 2008). Os critérios para escolha do substrato devem ser realizados de acordo com as exigências da semente, com relação ao tamanho, quantidade de água, sensibilidade a luz e de fácil realização das contagens e avaliação das plântulas (BRASIL, 2009).

Neste sentido, algumas pesquisas com outras espécies florestais já foram realizadas, como em Simira gardneriana (OLIVEIRA et al. 2016), Moringa oleifera Lam.(PEREIRA et al. 2015), Buchenavia tomentosa (AZEVEDO et al., 2015), Inga laurina (BARROZO et al. 2014); Casearia decandra (HALISKI et al., 2013); Diptychandra aurantiaca (OLIVEIRA et al. 2013); Piptadenia moniliformis Benth. (AZERÊDO et al. 2011), Dinizia excelsa Ducke (VARELA et al., 2006); Mimosa caesalpineaefolia (ALVES et al., 2002).

Devido a falta de padronização para condução do teste de germinação desta espécie nas Regras para Análise de Sementes, objetivou-se avaliar diferentes temperaturas e substratos na germinação e vigor de sementes de G. ulmifolia Lam. 


\section{MATERIAL E MÉTODOS}

Os frutos de Guazuma ulmifolia foram coletados em cinco árvores matrizes localizadas no município de Limoeiro do Norte-CE ( $5^{\circ} 08^{\prime} 44^{\prime \prime} \mathrm{S}$ e $38^{\circ} 05^{\prime} 53^{\prime \prime}$ W com altitude de 30,22 m). Logo após a colheita, extraiu-se as sementes dos frutos com auxílio de um martelo já que o fruto é do tipo seco indeiscente. Em seguida, retirouse as sementes chochas, mal formadas ou atacadas por insetos e microrganismos. As sementes permaneceram armazenadas em sacos plásticos em ambiente controlado $\left(18{ }^{\circ} \mathrm{C} ; 60 \%\right.$ U.R) até o início da realização dos experimentos. Para superação da dormência tegumentar, previamente as sementes foram imersas em água a $90{ }^{\circ} \mathrm{C}$, logo após retirou-se da fonte de calor e deixou na mesma água durante uma hora, segundo BRASIL, (2013).

Os substratos utilizados foram papel tipo mata-borrão (entre e sobre papel), papel toalha (tipo Germitest $\Theta$ ) e entre areia, cujos papéis foram previamente esterilizados em estufa a $105{ }^{\circ} \mathrm{C}$ por duas horas e areia a $200{ }^{\circ} \mathrm{C}$ por duas horas (BRASIL, 2009). As temperaturas testadas foram $25^{\circ}$ e $30{ }^{\circ} \mathrm{C}$ e $20-30{ }^{\circ} \mathrm{C}$. Os substratos de tipo papel foram umedecidos com quantidade de água na proporção de 2,5 vezes o peso do substrato seco.Já a areia foi umedecida com $60 \%$ da capacidade de campo (BRASIL, 2009).

No substrato mata-borrão a semeadura foi realizada entre papel (EP), cujas sementes foram colocadas sobre dois papéis e cobertas por uma terceira folha, já sobre papel (SP), as sementes foram semeadas sobre dois papéis tipo mata-borrão acondicionados em caixa gerbox. Para o papel toalha tipo Germitest $\Theta$, utilizou-se três folhas onde as sementes foram semeadas sobre duas e cobertas pela terceira folha na forma de rolo de papel (RP). No substrato areia a profundidade de semeadura foi de $1,0 \mathrm{~cm}$ e coberta com uma leve camada de areia. Após a semeadura, as sementes foram incubadas em câmara de germinação do tipo B.O.D (Biochemical Oxigen Demand) e mantidas sobre as temperaturas constantes de 25 e $30^{\circ} \mathrm{C}$ e alternada de $20-30^{\circ} \mathrm{C}$, com fotoperíodo de oito horas.

A contagem diária de sementes germinadas foi realizada do $7^{\circ}$ ao $21^{\circ}$ dia após a semeadura e os resultados foram expressos em percentagem. As variáveis analisadas foram: Germinação: somente consideradas como germinadas as sementes que produziram plântulas normais (BRASIL, 2009). Índice de velocidade de germinação: efetuou-se juntamente com o teste de germinação e foi calculado através da fórmula proposta por MAGUIRE (1962).

Tempo médio de germinação: calculado de acordo com a fórmula de LABOURIAU \& VALADARES (1976). Comprimento da parte aérea e da raiz: para o comprimento da parte aérea mediu-se com auxílio de uma régua graduada em milímetros, desde a inserção do colo até o ápice das folhas; já o comprimento de raiz, a medição se deu desde a inserção do colo até a extremidade da raiz e os resultados foram expressos em centímetros. Para a massa seca total: as mesmas plântulas mensuradas anteriormente foram colocadas em estufa com circulação de ar forçado a $65^{\circ} \mathrm{C}$ até 72 horas até manter o peso constante e os resultados expressos em gramas.

O delineamento experimental foi o inteiramente casualizado (DIC), em esquema fatorial $3 \times 4$ (temperaturas $\times$ substratos) totalizando 12 tratamentos, com quatro repetições de 25 sementes. A análise estatística foi efetuada através da análise de variância e as médias comparadas pelo teste de Tukey a $5 \%$ de probabilidade utilizando o software Sisvar (FERREIRA, 2011). 


\section{RESULTADOS E DISCUSSÃO}

Houve interação significativa $(P>0,05)$ apenas para o tempo médio de germinação e comprimento da parte aérea de plântulas. Porém, houve efeito significativo de forma isolada do substrato para o índice de velocidade de germinação e comprimento da raiz. Também houve efeito significativo de maneira isolada da temperatura sobre o comprimento da parte aérea (Tabela 1).

TABELA 1- Resumo da análise de variância da germinação $(G)$, índice de velocidade de germinação (IVG), tempo médio de germinação (TMG), comprimento de raiz (CR), comprimento da parte aérea (CPA) e massa seca total de plântulas (MSTP) oriundas de sementes de mutamba (Guazuma ulmifolia Lam.), submetidas a diferentes temperaturas $(T)$ e substratos $(S)$.

\begin{tabular}{lllllll}
\hline Fatores & G & IVG & TMG & CR & CPA & MSTP \\
\hline T & $64,75^{\text {n.s }}$ & $0,47^{\text {n.s }}$ & $0,23^{\text {n.s }}$ & $0,32^{\text {n.s }}$ & $4,15^{*}$ & $0,000009^{\text {n.s }}$ \\
S & $30,9^{\text {n.s }}$ & $2,08^{*}$ & $2,56^{*}$ & $0,56^{*}$ & $10,09^{*}$ & $0,000012^{\text {n.s }}$ \\
T $\times S$ & $24,63^{\text {n.s }}$ & $0,16^{\text {n.s }}$ & $1,27^{*}$ & $0,22^{\text {n.s }}$ & $1,58^{*}$ & $0,000005^{\text {n.s }}$ \\
\hline C.V & 16,4 & 22,2 & 9 & 19,9 & 10,5 & 0,31 \\
\hline M.G & 49,0 & 2,69 & 9,0 & 1,71 & 2,60 & 0,707
\end{tabular}

n.S= não significativo a $5 \%$ de probabilidade; ${ }^{*}=$ significativo a $5 \%$ de probabilidade.

C.V= Coeficiente de variação; $M . G=$ Média geral

A porcentagem média de germinação o foi de apenas $49 \%$, corroborando com a afirmação de CARVALHO (2007), no qual afirma que sementes de G. ulmifolia armazenadas por um ano ou mais apresentam germinação abaixo de $60 \%$ devido o rápido processo de deterioração após a colheita, o que também foi verificado neste trabalho, pois as sementes estavam com mais de um ano de armazenamento na época de instalação dos testes de germinação.

A não significância da temperatura sobre a germinação está de acordo com BORGES \& RENA (1993), em que sementes de um grande número de espécies florestais subtropicais e tropicais apresentam-se com potencial máximo de germinação na faixa de temperatura entre 20 e $30^{\circ} \mathrm{C}$. Com relação aos substratos, todos proporcionaram condições ideais de umidade e aeração, de forma que as sementes expressaram o seu máximo potencial germinativo, não diferindo estatisticamente entre si. Estes resultados, a princípio, revelam a capacidade da espécie em ampliar a sua distribuição em diferentes habitats, conferindo a mesma maior capacidade de suportar condições adversas de ambiente (AZERÊDO et al., 2011).

Em alguns trabalhos como no de HALISK et al. (2013) também não foi observada interação significativa entre temperaturas e substratos para porcentagem de germinação de sementes de $C$. decandra. Resultados encontrados por AZEVEDO et al. (2015) em sementes de B. tormentosa e OLIVEIRA et al.(2016) em sementes de $S$. gardneriana, diferem dos daqui apresentados pois encontraram interação significativa entre substratos e temperaturas para todas as variáveis analisadas.

O menor tempo médio de germinação foi obtido na temperatura de $30{ }^{\circ} \mathrm{C}$ combinado com o substrato sobre papel, embora não tenha diferido das temperaturas de 25 e $20-30{ }^{\circ} \mathrm{C}$ (Tabela 2). A temperatura exerce grande influência sobre a velocidade de embebição, sendo que para algumas espécies, a redução da 
temperatura, em função dos efeitos sobre a velocidade de embebição e de mobilização de reservas, provoca decréscimos acentuado na velocidade de germinação (MARCOS-FILHO, 2015), consequentemente aumentando o tempo para formação de plântulas normais.

VARELA et al. (2006) em sementes de $D$. excelsa Ducke, observaram menor tempo médio de germinação na temperatura de $30^{\circ} \mathrm{C}$ no substrato papel. PEREIRA et al. (2015) também obtiveram menores valores para esta variável, quando utilizaram o substrato papel nas temperaturas de $25^{\circ} \mathrm{C}$ e $30^{\circ} \mathrm{C}$ em sementes de $M$. oleifera Lam.

TABELA 2- Tempo médio de germinação de sementes de mutamba (Guazuma ulmifolia Lam.), obtidas a partir de sementes submetidas a diferentes temperaturas e substratos.

\begin{tabular}{lcccc}
\hline \multicolumn{5}{c}{ Temperaturas } \\
\hline Substratos & $25{ }^{\circ} \mathrm{C}$ & $30{ }^{\circ} \mathrm{C}$ & $20-30{ }^{\circ} \mathrm{C}$ & Médias \\
Rolo de papel & $5,93 \mathrm{aA}$ & $6,18 \mathrm{aAb}$ & $6,30 \mathrm{Aab}$ & $6,14 \mathrm{AB}$ \\
Entre areia & $5,40 \mathrm{bA}$ & $6,51 \mathrm{aA}$ & $7,0 \mathrm{aA}$ & $6,30 \mathrm{a}$ \\
Entre papel & $6,03 \mathrm{aA}$ & $5,49 \mathrm{aBC}$ & $5,21 \mathrm{aC}$ & $5,58 \mathrm{BC}$ \\
Sobre papel & $5,66 \mathrm{Aa}$ & $4,92 \mathrm{aC}$ & $5,39 \mathrm{aBC}$ & $5,32 \mathrm{C}$ \\
\hline Médias & $5,75 \mathrm{a}$ & $5,77 \mathrm{a}$ & $5,97 \mathrm{a}$ &
\end{tabular}

*Médias seguidas com a mesma letra minúscula na linha e maiúscula na coluna não diferem entre si, pelo teste de Tukey a $5 \%$ de probabilidade.

Observou-se maiores médias para o índice de velocidade de germinação (IVG) nos substratos sobre e entre-papel, não diferindo estatisticamente entre si (Tabela 3). De acordo com BRASIL (2009), os substratos entre papel (EP) e sobre papel (SP) são indicados para sementes pequenas que preferem ambientes úmidos, como é o caso da espécie em estudo, contribuindo para maior velocidade de embebição, proporcionando maior IVG.

ALVES et al. (2002) também obtiveram maiores IVG em sementes de $M$. caesalpiniaefolia Benth. utilizando o substrato sobre papel. AZERÊDO et al. (2011), também conseguiram maiores IVG nos substratos de papel, entre e sobre papel, em relação ao substrato areia para sementes de $P$. moniliformis Benth.

Além disso, os resultados obtidos para germinação e IVG, foram satisfatórios em mais de uma temperatura e substrato, concordando com BEWLEY \& BLACK (1994) de que as espécies, geralmente, possuem uma ou mais recomendações quanto ao substrato e/ou temperatura adequados à germinação. Foram observadas maiores médias para o comprimento de raiz nos substratos entre e sobre papel, não diferindo estatisticamente entre si. 
TABELA 3 - Índice de velocidade de germinação (IVG) e comprimento de raiz (CR) de plântulas de mutamba (Guazuma ulmifolia Lam.) oriundas de sementes submetidas diferentes temperaturas e substratos.

\begin{tabular}{lcc}
\hline Substratos & IVG & CR \\
\hline Rolo de Papel (RP) & $2,32 \mathrm{~b}$ & $1,61 \mathrm{ab}$ \\
Entre Areia (EA) & $2,34 \mathrm{~b}$ & $1,45 \mathrm{~b}$ \\
Entre Papel (EP) & $2,97 \mathrm{ab}$ & $1,90 \mathrm{a}$ \\
Sobre Papel (SP) & $3,12 \mathrm{a}$ & $1,88 \mathrm{a}$ \\
\hline Média geral & 2,69 & 1,71 \\
\hline
\end{tabular}

*Médias seguidas com a mesma letra minúscula na coluna e maiúscula na linha não diferem entre si, pelo teste de Tukey a $5 \%$ de probabilidade.

Foram observadas maiores médias para o comprimento de raiz nos substratos entre e sobre papel, não diferindo estatisticamente entre si. As raízes menores foram observadas no substrato entre areia, embora não tenha diferido do rolo de papel (Tabela 3). De acordo com AZERÊDO et al. (2011), o menor crescimento das raízes observado em areia, pode ser atribuído à menor capacidade de retenção de água, ao ressecamento observado na parte superior, apesar do reumedecimento ao longo do experimento, e a maior compactação observada nesse substrato, acarretando em menor absorção de água nesse substrato interferindo no alongamento celular.

A temperatura de $25{ }^{\circ} \mathrm{C}$ nos substratos entre areia e rolo de papel proporcionaram maiores valores do comprimento da parte aérea, não diferindo estatisticamente entre si (Tabela 4). Por outro lado, nos substratos entre e sobre papel, houve menor crescimento da parte aérea, comparando-se aos outros substratos, provavelmente isto ocorreu devido pouco espaço dentro da caixa plástica para crescimento da plântulas, já que não houve eliminação de plântulas durante o teste, uma vez que não se realizou a primeira contagem.

Estes resultados concordam em partes com os obtidos por OLIVEIRA (2016), cujas melhores combinações para comprimento de plântulas de $S$. gardneriana foram alcançadas quando as sementes foram submetidas às temperaturas de $25{ }^{\circ} \mathrm{C}$ nos substratos entre areia e rolo de papel. BARROZO et al. (2014), obtiveram maiores comprimentos da parte aérea de plântulas de I. laurina (Sw.) Willd. nos substratos areia e vermiculita nas temperaturas de 30 e $35{ }^{\circ} \mathrm{C}$, bem como no substrato entre papel na temperatura alternada de $20-30^{\circ} \mathrm{C}$.

TABELA 4 - Comprimento da parte aérea $(\mathrm{cm})$ de plântulas de mutamba (Guazuma ulmifolia Lam.), oriundas de sementes submetidas a diferentes temperaturas e substratos.

\begin{tabular}{lcccc}
\hline Substratos & $25^{\circ} \mathrm{C}$ & $30^{\circ} \mathrm{C}$ & $20-30^{\circ} \mathrm{C}$ & Médias \\
\hline Rolo de Papel & $4,13 \mathrm{Ba}$ & $2,00 \mathrm{bcC}$ & $2,68 \mathrm{abB}$ & $2,93 \mathrm{~B}$ \\
Entre Areia & $4,79 \mathrm{aA}$ & $3,14 \mathrm{Ab}$ & $3,10 \mathrm{aB}$ & $3,68 \mathrm{~A}$ \\
Entre Papel & $2,17 \mathrm{CA}$ & $2,44 \mathrm{Ba}$ & $2,20 \mathrm{bA}$ & $2,27 \mathrm{C}$ \\
Sobre Papel & $1,67 \mathrm{CA}$ & $1,75 \mathrm{Ca}$ & $1,17 \mathrm{cB}$ & $1,53 \mathrm{D}$ \\
\hline Médias & $3,19 \mathrm{a}$ & $2,33 \mathrm{~b}$ & $2,29 \mathrm{~b}$ & \\
\hline
\end{tabular}

*Médias seguidas com a mesma letra minúscula na coluna e maiúscula na linha não diferem entre si, pelo teste de Tukey a $5 \%$ de probabilidade. 
Apesar do crescente aumento de pesquisas avaliando temperaturas e substratos em sementes de espécies florestais, para que estas informações sejam padronizadas e incluídos nas Regras para Análises de Sementes, ainda são necessários a realização de testes com diferentes lotes, como por exemplo, com diferentes procedências. Segundo CARVALHO \& NAKAGAWA (2012) as espécies apresentam comportamento variável em relação à temperatura, embora a faixa de 20 a $30^{\circ} \mathrm{C}$ pareça ser a adequada para germinação de um grande número de espécies subtropicais e tropicais. Além disso, outros fatores associados, como luz e umidade, também devem ser investigados, de forma a proporcionar informações importantes de interesse biológico e ecológico que garantam, não somente a propagação da espécie, mas também o entendimento de sua estratégia de estabelecimento em condições naturais.

\section{CONCLUSÕES}

A temperatura de $25^{\circ} \mathrm{C}$ associada aos substratos entre ou sobre papel, são as combinações mais adequadas para avaliação da germinação e vigor de sementes de G. ulmifolia.

\section{REFERÊNCIAS}

AZEVEDO, M. I. R.; PAIVA, H. N. de; GOMES, J. M. Efeitos de substratos, luz e temperatura na germinação de sementes da espécies Buchenavia tomentosa Eichler (merindiba) em condições de laboratório. Science Agri-environmental, vol. 1, n. 1, p. 11-21, 2015. Disponível em < https://revista.unitins.br/index.php/agrienvironmental-sciences/article/view/42 > Acesso em 22 de dezembro 2016.

AZERÊDO, G. A.; PAULA, R. C.; VALERI, S. V. Temperatura e substrato para a germinação de sementes de Piptadenia moniliformis Benth. Scientia Forestalis, v. 39, n. 92, p. 479-488, 2011.Disponível em < http://www.ipef.br/publicacoes/scientia/nr92/cap11.pdf > Acesso em: 22 de janeiro 2016.

BARROZO, L. M.; ALVES, E. U.; SILVA, R. S.; ANJOS NETO, A. P.; SANTOS NETA, M. M. S.; SILVA, B. F. Substratos e temperaturas para testes de germinação e vigor de sementes de Inga laurina (Sw.) Willd. Bioscience Journal, v. 30, s. 1, p. 252-261, 2014. Disponível em < http://www.seer.ufu.br/index.php/biosciencejournal/article/view/18037/14567. > Acesso em: 25 de Agosto de 2017.

BEWLEY, J. D.; BLACK, M. Seeds: physiology of development and germination. New York: Plenum Press, 1994. 445 p.

BORGES, E. E. L.; RENA, A. B. Germinação de sementes. In: AGUIAR, I. B.; PINÃRODRIGUES, F. C. M.; FIGLIOLIA, M. B. Sementes florestais tropicais, Brasília, Cap. 3, p. 83-135, 1993.

BRASIL. Ministério da Agricultura, Pecuária e Abastecimento. Instruções para análise de sementes de espécies florestais. Brasília: MAPA/ACS, 2013. 77p. Disponível em < http://www.agricultura.gov.br/assuntos/laboratorios/arquivospublicacoes-laboratorio/florestal_documento_pdf-ilovepdf-compressed.pdf. > Acesso em: 25 de janeiro 2016. 
BRASIL. Ministério da Agricultura, Pecuária e Abastecimento. Regras para análise de sementes. Ministério da Agricultura, Pecuária e Abastecimento. Secretaria de Defesa Agropecuária. Brasília: MAPA/ACS, 2009. 395p. Disponível em < http://www.agricultura.gov.br/assuntos/insumos-agropecuarios/arquivos-

publicacoes-insumos/2946_regras_analise_sementes.pdf. > Acesso em 20 de janeiro 2016.

CARVALHO, P. E. R. Mutamba: Guazuma ulmifolia. Colombo: Embrapa Florestas, 2007. 13 p. (Embrapa Florestas. Circular Técnica, 141). Disponível em < http://www.infoteca.cnptia.embrapa.br/infoteca/bitstream/doc/312825/1/Circular141. pdf. > Acesso em: 20 de janeiro de 2016.

CARVALHO, N. M.; NAKAGAWA, J. Sementes: ciência, tecnologia e produção. 5. ed. Jaboticabal: FUNEP, 2012. 590 p.

FERREIRA, R. A.; VIEIRA, M. G. G. C.; PINHO, E. V. R. V.; TONETTI, O. A. O. Morfologia de sementes e de plântulas e avaliação da viabilidade da semente de sucupira branca (Pterodon pubescens Benth - Fabaceae) pelo teste de tetrazólio. Revista Brasileira de Sementes, v. 23, n. 1, p. 108-115, 2001. Disponível em: < http://www.abrates.org.br/revista/artigos/2001/v23n1/artigo15.pdf > Acesso em: 22 de janeiro 2016.

FERREIRA, E. G. B. S.; MATOS, V. P.; SENA, L.H.M.; SALES, A. G. F.A.Germinação de sementes e desenvolvimento inicial de plântulas de crista-degalo em diferentes substratos. Scientia Agraria, v. 9, n. 2, p. 241-244, 2008. Disponível em:< http://ccarevista.ufc.br/seer/index.php/ccarevista/article/view/4468> Acesso em:22 de janeiro 2016.

FERREIRA, D. F. Sisvar: A computer statistical analysis system. Ciência e Agrotecnologia, Lavras v. 35, n. 6, p. 1039-1042, 2011.

GUEDES R. S.; ALVES, E. U.; GONÇALVES, E. P.; COLARES, P. N. Q.; MEDEIROS, M. S.; VIANA, J. S. Germinação e vigor de sementes de Myracrodruon urundeuva Alemão. Revista Árvore, v. 35, n. 5, p. 975-982, 2011. Disponivel em< http://www.scielo.br/pdf/rarv/v35n5/a03v35n5.pdf > Acesso em: 22 de janeiro 2016.

GUEDES, R. S.; ALVES, E. U.; GONÇALVES, E. P.; FRANÇA, P.R.C.; MOURA, M.F.; SANTOS, S.S.Germinação de sementes de Dalbergia nigra (Vell.) Fr. All. Acta Scientiarum. Biological Sciences, v. 33, n. 4, p. 445-450, 2011. Disponível em :< http://periodicos.uem.br/ojs/index.php/ActaSciBiolSci/article/viewFile/5834/5834> Acesso em : 21 de janeiro de 2016. DOI: 10.4025/actascibiolsci.v33i4.5834

HALISKI, S.; COSMO, N. L.; GOGOSZ, A. M.; REGO, S.S.; NOGUEIRA, A. C; KUNIYOSHI, Y. S. Caracterização morfológica de frutos, sementes, plântulas e germinação de sementes de Casearia decandra. Pesquisa Florestal Brasileira, Colombo, v. 33, n. 75 , p. 253-259, 2013. Disponível em < http:pbfb.cnpf.embrapa.br/pfb/idex.php/pfb/article/viewFile/451/324. > Acesso em: 20 de janeiro 2016. Doi: 10.4336/2013.pfb.33.75.451.

LABOURIAU, L. G.; VALADARES, M. E. B. On the germination of seeds Calotropis procera (Ait.) Ait.f. Anais da Academia Brasileira de Ciências, v. 48, p. 263-284, 1976. 
LORENZI, H. Árvores brasileiras: manual de identificação e cultivo de plantas arbóreas nativas do Brasil. Nova Odessa: Ed Plantarum, 2002. v. 1, p. 343.

MAGUIRE, J. D. Speed of germination aid in selection and evaluation for seedling and vigour. Crop Science, Madison, v. 2, n. 2, p. 176-177, 1962.

NASSIF, S. M. L.; VIEIRA, I. G.; FERNANDES, G. D. Fatores externos (ambientais) que influenciam na germinação de sementes. Disponível em: <http://www.ipef.br/ tecsementes/germinacao.asp >. Acesso em: 03 ago. 2014.

OLIVEIRA, A. K. M.; RIBEIRO, J. W. F.; PEREIRA, K. C. L.; SILVA, C.A. A. Effects of temperature on the germination of Diptychandra aurantiaca (Fabaceae) seeds. Acta Scientiarum Agronomy, v. 35, n. 2, p. 203-208, 2013. Disponível em:< http://www.scielo.br/scielo.php?script=sci_arttext\&pid=S1807-86212013000200009. $>$ Acesso em 20 de janeiro 2016. DOI: http://dx.doi.org/10.4025/actasciagron.v35i2.15977

OLIVEIRA F. N. de; FRANÇA, F. D. de; TORRES, S. B.; NOGUEIRA, N. W.; FREITAS, R. M. O. de. Temperatura e substratos na germinação de sementes de pereiro-vermelho (Simira gardneriana M. R. Barbosa \& Peixoto). Revista Ciência. Agronômica, v. 47, n. 4, p. 658-666, out-dez, 2016. Disponível em: < http://www.ccarevista.ufc.br/seer/index.php/ccarevista/article/view/4314.> Acesso em 20 de janeiro 2016.

PEREIRA, K. T. O.; SANTOS, B. R. V.; BENEDITO, C. P.; LOPES, E. G.; AQUINO, G. S. M. Germinação e vigor de sementes de Moringa oleifera Lam. em diferentes substratos e temperaturas. Revista Caatinga, v. 28, n.2, p.92 - 99, 2015. Disponível em:<http://periodicos.ufersa.edu.br/revistas/index.php/sistema> Acesso em: 03 de janeiro 2016.

VARELA, V. P.; RAMOS, M. B. P.; MELO, M. F. Efeito de substratos e temperaturas na germinação de sementes de Dinizia excelsa Ducke. Revista Ciências Agrárias, v. $46, \quad$ n. $46, \quad$ p.171-179, 2006. Disponível em:< https://periodicos.ufra.edu.br/index.php?journal=ajaes\&page=article\&op=view\&path $\% 5 B \% 5 D=258>$ Acesso em: 24 de janeiro 2016. 